\title{
Thundermist Health Center: Extending Pharmaceutical Services To Underserved Patients
}

Charles J. Quigley, Jr. Ph D., Bryant University, USA

Frank G. Bingham, Jr. Ed.D., PhD., Bryant University, USA

\begin{abstract}
This paper describes a not-for-profit healthcare provider's strategy to provide its economically disadvantaged patients with access to low cost pharmaceuticals. Initially, an in-house pharmacy was established, supported by a satellite distribution system using a telepharmacy solution to extend medications to its patients at remote sites. New federal legislation which provided access to low cost insurance through Medicare Part D to many of the provider's disadvantaged patients, along with state licensing requirements forced the healthcare provider to reassess the economics of its pharmaceutical distribution system and seek other alternatives. Among the alternatives the healthcare provider considered was partnering with for-profit pharmaceutical companies in order to reach their patients.
\end{abstract}

Keywords: Case study, Not-for profit health care provider, Marketing strategy, Health care marketing, Pharmaceutical distribution, telepharmacy solutions, Strategic partnering, Satellite distribution, Relationship marketing.

\section{INTRODUCTION}

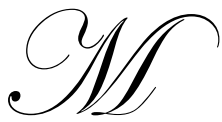

aria Montanaro, CEO of Thundermist Health Center (T-Mist), was at her desk when the phone rang. "Maria, this is Ken Anderson from Walgreens." Maria was expecting the call. "Ken, the Board is looking at all facets of your proposal and will not be ready to make a decision before their meeting next month." She knew this was not going to please him as Ken and his staff at Walgreens had spent many weeks with T-Mist managers discussing details of a proposed partnership for distributing pharmaceuticals to TMist's patients. However a new player, CVS, a major competitor of Walgreens, had entered the picture.

Chris Bodine, President of CVS had approached Montanaro and asked if T-Mist would consider partnering with their organization. CVS, which was headquartered in Cumberland, Rhode Island, the town next to T-Mist's largest primary care facility, had an established relationship with the organization. CVS had been a substantial donor to the not-for-profit health center in the past. T-Mist's Director of Development, Linda Reilly, had pointed out that the impending relationship with Walgreens could jeopardize CVS's future philanthropy. Maria also had to consider the wishes of her medical staff which had recommended maintaining the pharmacy as a not-for-profit, inhouse operation. However, her major concern was the potential impact of the decision on the future of the pharmaceutical distribution operation. What impact would this have on T-Mist's patients, especially their low income, disadvantaged patients.

Maria Montanaro had been President of Thundermist for the past ten years. Her career in community health spanned 19 years at the executive management level. She had served on numerous non-profit boards throughout both Rhode Island and New England and had worked with international medical relief organizations. Her responsibilities as CEO of one of the largest not-for-profit healthcare providers in Rhode Island required her to provide leadership and direction to the 150 employees of T-Mist. She spent much of her time with local, state, and federal legislative leaders securing necessary funding to support their activities. With the assistance of Linda Reilly, 
she had also devoted much time to developing relationships with local and state business organizations. Over the last couple of years, these efforts began to pay dividends as a number of large organizations had provided T-Mist with valuable resources. CVS was one of the major contributors providing both funding and pharmaceutical products to T-Mist.

As CEO, Montanaro was scheduled to present the organization's strategic plan for the upcoming year to the Board of Trustees. Included in this plan would be the direction she and her staff would recommend for the healthcare organization's pharmacy program. In addition to the expected questions about the strategic direction of T-Mist, funding priorities, and program initiatives, many of the Trustees would be concerned about the future of the pharmacy program and the financial implications of her recommendation.

Many members of the Board had been reluctant to endorse T-Mist's original proposal to provide pharmaceuticals to their patients by creating an in-house pharmacy operation, believing that the private sector was better able to provide the needed service. However, just four years prior to this meeting, Montanaro and her Senior Vice President/Chief Medical Officer, Dr. David Bourassa, had been able to convince the Board to support their request because of the expected benefits to both T-Mist and its patients. She was now unsure of what their reaction would be if her recommendation was to terminate the pharmacy program and return to private sources for pharmaceuticals.

The economic ramifications of her recommendation on T-Mist and their patients would be a key to getting Board support. Having selected many of the Board members herself, she knew they were well aware of what was happening both locally and nationally to the health care system. Costs for health care had been rising at the fastest rate in history, accounting for 16 percent of the gross domestic product (GDP). Health care costs were expected to increase to twenty percent of GDP within ten years. The ability to afford the rising costs of health care was, however, not equally shared among consumers. Coupled with the dramatic increase in costs was the increasing number of uninsured and underinsured. Nationally, 37 million people lived in poverty, with an additional $25 \%$ of the US population depending on government insurance programs through Medicare and Medicaid. The majority of the uninsured and underinsured were the young and the old (National Center for Health Statistics, 2006). This was the market that T-Mist was committed to serving, a fact well known to her Board members.

Exacerbating the financial impact on individuals and families within this market was the increased cost of prescription drugs. Costs for pharmaceuticals had increased more rapidly than general healthcare costs, rising from $\$ 12$ billion in 1980 to $\$ 179.2$ billion in 2003, a nearly 1400\% increase (National Center for Health Statistics, 2006).

\section{THUNDERMIST HEALTH CENTER}

T-Mist was founded in 1969 as a private not-for-profit family health care clinic. The Center was established to provide affordable comprehensive primary medical care to the local patient population. Its mission "to provide comprehensive primary care when and where it is needed most, in an affordable manner, in a language everyone can understand, with dignity and respect" remained the driving force behind the organization (Thundermist Health Center, 2008). Their targeted clients were individuals and families that lived in poverty, were medically uninsured, were from a minority population, or were from a cultural or socio-economic status that created barriers to obtaining primary health care services.

Over the years, the Center had grown to be one of the largest community health care providers in Rhode Island, providing medical, dental, and social services to nearly 25,000 patients. They had approximately 235 employees located in four facilities within the state. Since their inception, program offerings had expanded to include adult medicine, pediatrics, and dental care. In 1998, the organization achieved national accreditation from the Joint Commission on Accreditation of Hospitals, which was considered the "Gold Standard" in health care accreditation for providers.

Dr. Bourassa, long recognized as an outstanding leader and provider in community health by his peers, was a graduate of Case Western Reserve University School of Medicine. He was appointed Medical Director in 1998 and named Senior Vice President/Chief Medical Officer of T-Mist in 2003. 
Twelve staff physicians with admitting privileges at local hospitals provided primary medical care. The organization maintained a multilingual staff that could communicate with patients who spoke Spanish and Portuguese, along with those of Asian ancestry. Food assistance was provided through a food pantry. Nutritional counseling, psychological counseling, social service case management, extended support services to people living with HIV, home visits, patient education and community prevention programs were provided through partnerships with other agencies. Consistent with their mission, T-Mist assisted their patients in obtaining services from public assistance programs and other social service agencies.

T-Mist was headquartered in Woonsocket, Rhode Island, where the vast majority of their patients lived. Woonsocket was an old textile mill city, somewhat geographically isolated in the northern area of the state. The city typified the dying mill towns of the Northeast; old and decaying housing stock with a downtown area lacking new business development with no large industrial base for the community. Nearly 40 percent of the 44,000 residents of the city had incomes at or below $200 \%$ of the federal poverty level. From the Woonsocket facility, medical care, behavioral health, social services, and nutritional counseling were provided, in addition to a pharmacy and a dental clinic. During 2006, T-Mist served over 13,000 medical and dental patients from the Woonsocket facility (see Table $1)$.

Table 1

Facility Usage (Patients)

\begin{tabular}{lccccc}
\hline & $\mathbf{2 0 0 2}$ & $\mathbf{2 0 0 3}$ & $\mathbf{2 0 0 4}$ & $\mathbf{2 0 0 5}$ & $\mathbf{2 0 0 6}$ \\
\hline MEDICAL: & & & & & \\
Woonsocket & 10533 & 11353 & 10251 & 10846 & 10578 \\
South County & 4421 & 4360 & 4299 & 4513 & 4139 \\
West Warwick & 0 & 0 & 1145 & 1456 & 1967 \\
DENTAL: & & & & & 2644 \\
Woonsocket & 2627 & 2078 & 2219 & 3110 & 3134 \\
South County & 2334 & 2465 & 2630 & 987 & 1533 \\
West Warwick & 0 & 0 & 986 & 1326 \\
\hline
\end{tabular}

(Thundermist Health Center, 2007)

T-Mist expanded beyond Woonsocket to offer medical and dental services to patients throughout Rhode Island. Expansion began in 2002 when they merged with the Health Center of South County to form Thundermist South County. This facility was located in Wakefield, Rhode Island, the geographic and population center of the State's southern most county. This center served approximately 7,500 patients out of the estimated 10,000 medically under-served, low income people with significant health care needs in South County.

In 2004, T-Mist opened a facility in West Warwick, Rhode Island to serve the geographic center of the State. T-Mist estimated that approximately 30\% of the city's population of 30,000 fell below $200 \%$ of the federal poverty level and that among this targeted group, approximately 50\% were uninsured. During their first full year of operation, T-Mist West Warwick served over 2,100 medical and dental patients, and in 2006 served over 3,500 patients.

In the same year that the West Warwick facility was opened, T-Mist partnered with Northwest Community Health Care for the dispensing of pharmaceuticals only. This organization was located in Pascoag, Rhode Island, in the northwest section of the state. T-Mist estimated that approximately 7,000 medically underserved residents with income levels that were at or below $200 \%$ of the federal poverty level lived in the area. The center served over 6,200 patients in the first year, of which $18 \%$ were recipients of Medicare. An additional $20 \%$ of the center's patients were uninsured.

T-Mist's overall patient population was disproportionately poor. Over $85 \%$ of their clients in the northern sector of their service area and $73 \%$ of their clients in the southern part of their service area were at or below $200 \%$ of the Federal poverty limit. 


\section{PHARMACEUTICAL SERVICES}

One of the most pressing concerns that many of T-Mist's patients faced was acquiring necessary medications and pharmaceuticals to treat their medical and dental conditions. Uninsured adults had limited access to affordable medications and relied heavily on local community health centers for help. The elderly were especially at risk. With a variety of health and social service needs, the elderly tended to be the most dependent on the need for pharmaceuticals. Many of T-Mist's elderly patients lived on fixed incomes, with many of these living below the poverty level.

Since it's founding, T-Mist had expanded its medical and dental services, adding mental health and social services to its product mix to meet the growing needs of targeted customers; however, until 2002, they were unable to provide their patients with necessary pharmaceutical products. Patients were referred to private, for-profit pharmacies to fill their prescriptions. Rhode Island Pharmaceutical Assistance for the Elderly (RIPAE), funding provided by the state, offered limited financial support for prescription drugs for the elderly. Eligible seniors, whose incomes fell at or below $200 \%$ of the federal poverty level, paid up to $70 \%$ of the discounted RIPAE price for prescriptions if they were in the RIPAE formulary. However, this only covered medications for the treatment of a limited number of conditions. For patients who needed drugs not covered by RIPAE, and/or those who could not afford prescriptions written by T-Mist physicians and dentists, vouchers were provided for use at neighborhood forprofit pharmacies.

Driven by the mission of their organization, Maria and Dr. Bourassa felt compelled to address this situation by providing their patients with low cost medications to support their medical and dental treatment. To provide low cost pharmaceutical services to their service areas, Montanaro and her staff were confronted with three major barriers. The first was the economics of setting up and operating a pharmaceutical service; the second was compliance with the state's statutory requirements for operating a pharmacy; and the third was obtaining approval from the Board of Trustees.

Over the course of several weeks and after numerous meetings with senior administrative and medical staff members, one creative option emerged. This option was to create an in-house pharmacy within the Woonsocket facility. This would allow T-Mist to pass on the savings realized from low cost procurement to their patients.

Several members of T-Mist's Board of Directors privately expressed their concern to Maria concerning the in-house pharmacy option. They thought the current system, where prescriptions written by the medical and dental staff were filled by neighborhood pharmacies, was effective. They also believed that the discount provided through the Pharmaceutical Assistance to the Elderly (RIPAE) program, which provided discounted prices to senior citizens and other qualifying low-income families, was sufficient. Montanaro and Dr. Bourassa explained to the concerned Board members that only certain medications were eligible for discounts, and only to those patients that met the state's criteria for assistance. She also explained that T-Mist was paying, on average, $\$ 24,000$ per month to reimburse local pharmacies for the vouchers that were provided to patients to cover their prescriptions. The inhouse pharmacy option would eliminate these payments and ultimately save the organization money. She also believed that the anticipated cost savings T-Mist could pass along to their patients would reduce patient cost below what they were paying to the private, for-profit pharmacies. Based primarily on the expected cost savings T-Mist would pass on to their patients, Montanaro and Ernie Balasco, her Chief Financial Officer, were able to obtain the reluctant approval of the Board to investigate this delivery method.

Montanaro, Ernie Balasco, and Sam Limiadi, Chief Operating Officer of T-Mist, started their investigation by contacting the Federal Office of Pharmacy Affairs, a branch of the Health Resources and Services Administration (HRSA). Through this agency, they were able to identify other health care centers throughout the country that had established in-house pharmacy operations. After speaking with the operating officers of these providers and visiting several sites, Montanaro and her senior managers concluded that they could establish an in-house pharmacy operation as a Federal 340B entity, allowing T-Mist to purchase most medications at deeply discounted prices. Also, by entering into contracts with a large national buying association for not-for-profit community healthcare centers, T-Mist would be able to buy drugs from manufacturers at prices often below those available through the 
340B Federal program. Table 2 shows the T-Mist cost, patient price, and normal retail price for the most frequently prescribed pharmaceuticals (2007 prices).

Table 2

Prices for Pharmaceuticals (Most Frequently Dispensed Medications)

\begin{tabular}{|c|c|c|c|c|}
\hline Medication & Treatment of & T-Mist Cost & Patient Price & Retail Price \\
\hline Norvasc & Chest pain (angina) & $\$ .00 *$ & $\$ 10.00$ & $\$ 296.74$ \\
\hline Lipitor & Cholesterol-Lowering & $\$ .00 *$ & $\$ 10.00$ & $\$ 206.00$ \\
\hline Glucotrol & Type II diabetes & $\$ .00 *$ & $\$ 10.00$ & $\$ 49.29$ \\
\hline Accupril & Hypertension & $\$ .00 *$ & $\$ 10.00$ & $\$ 58.59$ \\
\hline Zoloft & Anti-depresant & $\$ .00 *$ & $\$ 10.00$ & $\$ 109.99$ \\
\hline Zyrtec & Allergies & $\$ .00 *$ & $\$ 10.00$ & $\$ 89.59$ \\
\hline HCTZ & Fluid retention and high blood pressure. & $\$ 0.30$ & $\$ 10.00$ & $\$ 10.99$ \\
\hline Loratadine & Allergies & $\$ 0.50$ & $\$ 10.00$ & $\$ 12.09$ \\
\hline Metoprolol & Hypertension & $\$ 0.40$ & $\$ 10.00$ & $\$ 10.99$ \\
\hline ProAir & Asthma & $\$ 14.41$ & $\$ 10.00$ & $\$ 40.79$ \\
\hline OrthoTrilo & Birth Control & $\$ 18.94$ & $\$ 10.00$ & $\$ 53.59$ \\
\hline Lisinopril & Hypertension & $\$ 0.78$ & $\$ 10.00$ & $\$ 17.59$ \\
\hline
\end{tabular}

*Obtained through Pfizer Share the Care Program at No Cost.

Source: Thundermist Internal Records

Providing in-house pharmaceutical products and services would require a secure physical structure. After exploring several options, Montanaro, Bourassa, and Limiadi selected a location within their Woonsocket primary care facility next to the main entrance. There was sufficient room available to both partition it off and to provide the necessary security, along with providing easy access to patients. The projected cost of construction was less than building another off-site facility

Another cost component that had to be considered was labor costs associated with running a pharmacy. State law required that only a licensed pharmacist could dispense prescription medications. There was a limited availability of licensed pharmacists in the local market and the annual cost to employ one was estimated to be between $\$ 90,000$ and $\$ 100,000$ annually. They were not sure if one pharmacist would be sufficient or if additional professional pharmacy employees would be required.

T-Mist hired LoriAnn Collins as Pharmacy Manager to assist them with planning and setting up the pharmacy program. Collins was a licensed pharmacist, had recently attained the MBA, and had been director of pharmacy operations for a major educational institution. Based on the plans and budget developed by Collins, Tmist filed an application with the state to create an in-house pharmacy as a 340B entity in June of 2002. A grant for construction cost of approximately $\$ 18,000$ was obtained from HRSA, Office of Pharmacy Affairs. Construction began in the summer of 2002 and by early fall of the same year, the pharmacy opened in the Woonsocket facility. To cover operating costs, Collins recommended that a modest fee be charged to patients, the magnitude of which would depend on the cost of labor and the expected volume the pharmacy would generate.

Ms. Collins was hired to both manage the operation of the pharmacy and to dispense medications. To inform patients of this new planned service, T-Mist provided physicians with fliers to distribute to patients as they were seen. The fliers described the new pharmacy facility and the services offered. This, along with an accompanying public relations release to local media, was the only promotional activities used to inform the local community of the new operation.

The target market for the pharmacy was active patients of Thundermist, as only prescriptions written by Thundermist physicians or external specialists (as long as the prescription was co-signed by an in-house physician) could be filled. Table 3 describes pharmacy usage from October 2002 through the second quarter of 2006. Limiadi estimated that by the end of 2006 approximately $14 \%$ of their patient population in the northern service area would be users of the in-house facility. 
In December of 2002, Montanaro and Dr. Bourassa met with Collins, Limiadi, and Balasco to review the performance of the pharmacy operation. Although they had not yet covered fixed costs, pharmacy usage had increased each month and both Montanaro and Dr. Bourassa were pleased. Based on the apparent success of the Woonsocket facility, Montanaro asked Collins and Balasco to begin planning the expansion of pharmaceutical care to their other service areas.

Table 3

Pharmacy Usage - Woonsocket (prescriptions filled)

\begin{tabular}{ccccc}
\hline Fiscal Year & Total \# of Rx's & New & Refill & Free* $^{*}$ \\
\hline FY 03** & 6236 & 4184 & 2052 & 375 \\
FY 04 & 14452 & 8099 & 6353 & 2054 \\
FY 05 & 22561 & 12569 & 9992 & 5890 \\
FY 06 & 21676 & 12014 & 9662 & 6061 \\
\hline
\end{tabular}

* Samples and Manufacturer's Program

** FY03 - October 02 through August 03

FY - September 1 through August 31

Source: Thundermist internal records 2007

Knowing that the ultimate success of the pharmacy operation would depend on their ability to reduce costs, Collins, with the support of both Montanaro and Bourassa, sought non-traditional ways to extend pharmacy services. Telemedicine (providing health care at a distance) was identified as an alternative to on-site, full service pharmacy operations. This option would provide access to patients throughout the state without the necessity of an extensive on-site facility staffed by licensed pharmacists. Telepharmacy, an application of telemedicine, eliminated the cost of having a licensed pharmacist at off-site facilities. This would allow T-Mist to minimize operating costs, while extending the benefits of low cost procurement to their 25,000 patients statewide.

To implement this solution, hardware which provided remote dispensing of a 100-drug formulary using digital communication technology was obtained from Telepharmacy Solutions, Inc. This system allowed Collins to dispense a drug through a machine located at each remote facility. Patients at the remote sites talked with Collins or another pharmacist in the Woonsocket facility using a remote video link. The system enabled the pharmacist to control dispensing of starter doses or refills directly at the point of care, and when necessary, to forward refills through the mail to patients. The cost for each unit was $\$ 45,000$ installed. The ongoing software service costs were $\$ 15,000$ per site per year.

In the spring of 2003, a grant was obtained from the Health Resources and Services Administration (HRSA) for funding of the hardware and the initial software for remote dispensing. A condition for obtaining the funding was the establishment of a collaborative network of regional health centers. T-Mist had merged with the South County organization (T-Mist South County) in 2002, so the creation of the West Warwick Health Center (2004) along with an alliance with the Northwest Health Center (2004) satisfied the conditions of the funding agency. T-Mist purchased and installed units for each of the remote medical facilities between May and October of 2003.

Before pharmaceuticals could be dispensed at the remote sites, state approval was needed. While Montanaro, Bourassa, and Collins thought this would not be an issue, the R.I. State Licensing Board thought otherwise. They was concerned with the security and safety of the system; specifically who would have access to the drugs and who would be releasing the medication to patients at the remote sites. The state was also concerned with how information would be provided to patients regarding their medication. Following intensive discussions with the Licensing Board, the state finally granted approval for T-Mist to operate the remote dispensing system, but only if they agreed to employ a "licensed pharmacy technician in training" for each site. These technicians would be responsible for dispensing drugs to the patients at each of the remote locations, under the supervision of a licensed pharmacist at the Woonsocket facility. 
Thundermist hired and trained three individuals to qualify as "licensed pharmacy technicians" and assigned them to the three remote sites. Collins and Balasco estimated the cost to employ these individuals at $\$ 50,000$ each (the cost of the technician assigned to the Northwest Community Health Center was shared by T-Mist and its partner). While training costs were difficult to determine, they estimated the training cost to be between $\$ 10,000$ and $\$ 15,000$ per technician. Operation of the remote dispensing system began in October 2003.

Drug manufacturers and wholesalers shipped product in bulk to the Woonsocket pharmacy, as volume did not warrant the individual pre-packaging of formulary. Collins bar-coded the labels and filled the prescription containers for delivery to the remote sites. Legal requirements mandated that the machines at these sites be filled by Collins or another licensed pharmacist. Because of limited machine capacity, it was necessary for the pharmacist to visit each of these sites to update inventory and verify expiration dates. Travel time to each site averaged two hours round trip. The frequency of these visits depended on the volume of usage at each location. Collins estimated that during the first several months of operation she would have to visit each site at least every other week. This was required because some formulary in the remote dispensing units would have short expiration periods, and undispensed prescriptions would have to be removed from the machines. As volume picked up, the frequency of these trips would also have to increase.

Patients who used the remote health centers were informed by their medical and dental providers whenever the prescribed medication was available through the dispensing system at a particular facility. Availability of drugs through the remote dispensing system was also explained in pamphlets distributed to patients at each remote center. Table 4 provides patient usage of the remote sites.

Table 4

Pharmacy Usage - Remote Locations (prescriptions filled)

\begin{tabular}{|c|c|c|c|c|c|c|c|c|}
\hline & \multicolumn{2}{|c|}{ South County } & \multicolumn{2}{|c|}{ W. Warwick } & \multicolumn{2}{|c|}{ Northwest } & \multirow[t]{2}{*}{ 3rd party collected } & \multirow{2}{*}{ total revenue } \\
\hline & picked up & not $\mathrm{p} / \mathrm{u}$ & picked up & not $\mathrm{p} / \mathrm{u}$ & picked up & not $\mathrm{p} / \mathrm{u}$ & & \\
\hline FY04* & 159 & 32 & 112 & 22 & 5 & 0 & $\$ 0.00$ & $\$ 0.00$ \\
\hline $\mathrm{FY} 05 * *$ & 759 & 144 & 406 & 83 & 340 & 6 & $\$ 1,318.47$ & $\$ 4,238.09$ \\
\hline $\mathrm{FY} 06 * *$ & 629 & 72 & 353 & 62 & 274 & 11 & $\$ 946.17$ & $\$ 1,505.70$ \\
\hline
\end{tabular}

* FY04 - June 03 through August 04

* FY - September through August

Source: Thundermist internal records 2007

\section{NEW HEALTHCARE CENTER}

The original treatment center for T-Mist had been located in a refurbished mill building close to a highly trafficked highway in an older section of Woonsocket. The facility had limited parking for patients and staff. The layout of the facility was problematic. When new staff was added and services expanded, new offices, examination rooms, and treatment rooms were added wherever space was available. This produced a layout that was confusing to patients, as they were required to travel the length of the building to go from an exam room to a treatment area and then return to meet with the medical professional. The layout was also wasteful of the medical staff time, often producing backups in patient treatment. The in-house pharmacy occupied approximately 500 square feet of space to the right of the entrance. The sign-in stations for patients seeking medical or dental assistance were located to the right of the entrance.

In 2005 Thundermist moved into a new medical facility in the center of Woonsocket. The new facility was easily accessible to patients and provided amble parking for both staff and patients. The facility was also on the city's major bus routes. This facility incorporated the latest technology in efficient and effective design that welcomed patients, provided for reduced waiting times, and avoided unnecessary delays. The new facility was designed to provide efficient, high quality patient care in Pediatrics, Women's Health, Adult Medicine, Social Services, Dental Care, and Mental Health. The in-house pharmacy was included in the new facility. The pharmacy occupied approximately 900 square feet and was located on the first floor, next to the main entry/exit. All patients 
had to pass the pharmacy on their way to and from the welcoming/sign-in/sign-out stations located on the second floor.

Montanaro had been pleased with the move to the new facility. After the first year, her staff, especially the professional staff, had voiced their pleasure with the facility, and surveys of patients revealed that they too were pleased with the new center. Dr. Bourassa was also pleased, as he was having an easier time recruiting and retaining existing staff, a situation both of them ascribed to the new facility. Montanaro's pleasure with the new center, however, was tempered by the financial performance of the pharmacy operation. A review of financial statements prepared by Balasco indicated that the pharmacy had lost nearly $\$ 200,000$ from September 2005 through August 2006. While this was less than the $\$ 240,000$ the pharmacy had lost the previous fiscal year, she felt that pharmacy volume would grow and the financial performance would improve over time. When initially conceived, Montanaro, Bourassa, Balasco, and Collins had expected the pharmacy operation to break-even by the end of the second year of operation and begin to make a positive contribution by the end of 2004.

The financial review revealed that T-Mist received reimbursements for $50 \%-60 \%$ of the prescriptions filled from third party payers. For patients covered by third party insurers, T-Mist was reimbursed based on the average wholesale price (AWP) for the medication. The AWP was specific to each medication, however on average it amounted to $50 \%$ of the retail price of the medication. From the AWP, insurers would deduct a fee, or discount ranging from $15 \%$ to $25 \%$ of the AWP. Self-paying patients, those not covered by third party insurers, paid the $340 \mathrm{~B}$ price that T-Mist paid, plus the $\$ 5$ dispensing fee. If the patient could not afford the fee and the $340 \mathrm{~B}$ price of the medication, both were waived.

Initially, T-Mist charged a $\$ 5$ fee for each prescription filled. After the first full year of operation, Collins estimated that the pharmacy operation was losing $\$ 3$ for each prescription filled. The dispensing fee was raised in March of 2006, when Montanaro reluctantly agreed to raise the fee to $\$ 8$ per prescription. The fee was again raised in November of 2006 to $\$ 10$ for each prescription filled. Patients given prescriptions for drugs not stocked by the in-house or remote site units were given vouchers for neighborhood for-profit pharmacies. The cost of the vouchers and the loss of the dispensing fee for patients who could not afford to pay were estimated at $\$ 1000$ per month.

Balasco estimated that fixed costs, which included the cost of allocated rent for space, and labor, which included the pharmacist and licensed pharmacists in training, were approximately $\$ 400,000$ per year. Labor costs alone were estimated to be $\$ 100,000$ for the pharmacist, $\$ 65,000$ for a part-time pharmacist, and $\$ 50,000$ for each in-house pharmacy technician. Collins estimated that nearly forty percent of her time was spent in administrative tasks which included managing the dispensing of prescription drugs through the remote sites.

Dr. Bourassa was also concerned with the poor financial performance of the pharmacy. However, unlike Montanaro, who believed the financial problems were caused by the inability to generate sufficient volume through the remote sites, Bourassa believed the problems were caused by the inability to manage operating costs, especially at the remote sites. He felt that the cost burden imposed by the state requiring licensed technicians at each of the remote sites was the cause of the financial problems. He estimated that this cost the pharmacy operation an additional $\$ 150,000$ per year when training and benefit costs were added.

Although Montanaro believed that the expansion of the system to the remote locations and the failure to meet volume projections at these sites contributed to the inability to break even, she was pleased and encouraged by the growth in volume at the Woonsocket facility. Through 2005, volume had grown steadily, approaching nearly 23,000 prescriptions filled. However, volume declined during 2006. With the move to the new facility, volume was expected to increase.

The pharmacy operation had experienced several other major problems during 2006. LoriAnn Collins, Pharmacy Director and lead pharmacist, resigned to take another position in April and a part-time pharmacist, who had been hired the previous year to support the growth in volume at the Woonsocket facility, resigned two months later. The replacement pharmacist T-Mist hired to manage the pharmacy was placed on medical leave shortly after starting employment in May. Unable to recruit a full-time licensed pharmacist, partly because of a severe shortage of pharmacists in the Northeast, T-Mist was forced to temporarily close the pharmacy operation. The remote sites 
were also closed because medications could not be released without a pharmacist on site in the Woonsocket facility. During this period of time, patients that had been receiving their prescriptions through the in-house pharmacy were once again provided with vouchers and directed to local for-profit pharmacies to obtain their medications. When TMist was able to reopen the pharmacy six weeks later, additional staffing problems involving licensed pharmacy technicians forced them to limit the hours of operation.

Montanaro agreed with Dr. Bourassa's assessment concerning labor costs. She had shared with both Bourassa and Balasco her fear that even if costs could be brought under control, the loss of volume that had occurred both during and after the six week closure would hinder the effort to return to levels necessary to breakeven. What was most disturbing to her was the apparent loss of patients who had third party coverage. The financial information indicated that reimbursements from third party insurers fell following the six week closure. Some patients appeared to have left the in-house pharmacy for other pharmacies in the area. Cash payers, patients that had no other choice but to remain with the pharmacy to receive low or no cost pharmaceuticals, returned.

Montanaro realized T-Mist could not afford to underwrite a continuing deficit in the pharmacy operations. Although cash paying patients and patients who could not afford to pay were the targeted customers for the in-house pharmacy, patients covered by third party payers were critical sources of revenue. Without reimbursement from these insurers, funding for the pharmacy would have to be provided from other T-Mist programs. Bourassa believed that it was simply a question of time until these patients began to again use the in-house pharmacy, and with careful control of costs, volume could be increased to breakeven. Montanaro was not as confident.

What made any decision to curtail or further limit pharmacy services was the realization that their patients had benefited from the in-house pharmacy operation. Patients were paying reduced federal 340B pricing for their medications plus the $\$ 10$ dispensing. Collins had estimated that patients that used the in-house pharmacy saved an average of $30 \%-40 \%$ off normal retail prices. If patients were unable to afford the dispensing fee, it was waived. For uninsured and indigent patients, T-Mist leveraged patient assistant programs to access free medications from pharmaceutical companies. Collins estimated that they received approximately $\$ 450,000$ worth of no-cost drugs annually from these programs.

In early October, 2006, after completing the review of the fiscal year financial performance, Montanaro asked her administrative, medical, and dental staff to develop options to stem the pharmacy's operating losses. One option Dr. Bourassa and several senior members of the administrative and medical staff preferred was to focus on increasing volume at both the in-house facility and the remote dispensing sites. They felt that this would be the most appropriate action and would allow T-Mist to spread the labor costs over a greater unit volume without having to again increase the dispensing fee charged to patients. They also believed that this option was consistent with their organization's mission and that it would continue to allow them to charge prices below what other options would allow. They noted that the Woonsocket in-house pharmacy, other than 2006, had consistently grown its volume since opening in October 2002. Usage data indicated that up until the Woonsocket pharmacy was temporarily closed, most patients who received their initial prescriptions there continued to use the pharmacy for refills.

Proponents of this option pointed to the location of the pharmacy and the knowledge among patients, physicians, and staff of the availability of prescribed medications. At the Woonsocket facility, patients were reminded by staff "greeters," placed strategically at the entrance/exit to the sign-in station, to make sure they fill or refill their prescriptions at the pharmacy on the way out. Since the initial opening of the pharmacy, physicians, with consistent reminding from staff, had communicated to patients the convenience and economy of the in-house pharmacy.

Proponents also believed that the "spokes" of the pharmacy system (the remote access sites) had a positive impact on patients. Although volume growth at the remote sites was slow, the network provided low cost medications to patients in locations too small to support an in-house pharmacy. This, they argued, was the reason for creating the pharmacy program in the first place. They suggested that redesigning the layout at the remote sites to increase visibility, along with having the staff continue to aggressively promote remote pharmacy usage, would increase volume to a level comparable to the Woonsocket site. Also, with sufficient volume, it would be economically feasible to contract with a pharmaceutical prepackaging company to directly send medications to the 
remote sites, thus relieving the pharmacist in Woonsocket from the burden of prepackaging and labeling the medications. Some administrators also expressed their belief that the pharmacy should sell non-prescription drug products with a sufficient markup to alleviate the operating deficit. Some of the products they suggested selling included soda, magazines, snacks, and greeting cards.

Dr. Bourassa noted another advantage of this option; it provided greater control of the prescribing behavior of the medical staff. He believed that the in-house pharmacy operation gave medical staff the ability to use formulary control to better manage the cost of pharmaceutical therapy by influencing the prescribing behavior of their physicians. Patients benefited from better adherence to treatment plans when they received their prescriptions at the health center instead of going to an off-site pharmacy. He also believed that T-Mist was a more effective advocate for addressing patients' inability to pay than a for-profit pharmacy would be.

What concerned Montanaro about this option was the ability to control costs. The cost that was of most concern was the cost of the pharmacists. Both she and Ernie Balasco felt that the cost to meet the state's statutory requirements would continue to be a major burden. It appeared to them that due to the small size of the remote dispensing machines, the cost of prepackaging the medications, and the time spent by the pharmacist restocking the machine, they would have trouble reaching a breaking-even point unless major changes were made. Bourassa noted that if the formulary was not tightly controlled, medications stocked in the remote access machines would not turnover quickly and would exceed the expiration date, producing waste and additional cost. Although the system was user friendly, there was the added cost for training technicians as required by the state's licensing board. As only the pharmacist or a trained technician could release medications to patients, it was expected that staffing would remain a critical problem. While Dr. Bourassa liked the formulary control provided by the system, he was also concerned that the limited formulary stocked in the machines at the remote sites would continue to impact the medical options that staff members considered for patients.

Another factor that had to be considered was the impact of the recently enacted Federal Medicaid PART D program, which became operational on January 1, 2006, and which provided coverage for numerous formularies for citizens covered under Medicaid. Many of T-Mist's patients were affected by this program which covered the cost of drugs up to a break point of $\$ 2400$. From $\$ 2400$ to $\$ 3600$ (the "Donut Hole"), the individual paid out of pocket expenses. Above $\$ 3600$, the individual's expenses for drugs were not covered. This option also required a co-pay for many medications along with a monthly enrollment fee.

The competitive environment at the retail pharmaceutical level had also changed. Giant retailers, including Wal-Mart and Target, had entered the retail pharmacy market. Both chains provided generic drugs at a cost of $\$ 4$. Although many of T-Mist's patients would benefit from this option, newer drugs, which were still covered by their original patent, were not available as generics.

While attending a national conference of health center executives in October, 2006, another option had come to Montanaro's attention; the possibility of a partnership with a retail pharmaceutical company. At the conference she had met Ken Anderson, a long-time friend who was employed by Walgreens, a large national forprofit pharmacy. She shared with Anderson the problems her organization was having operating the in-house and remote site pharmacy operation. After he listened to Montanaro describe T-Mist's problems, he bluntly asked the CEO what business they were in. Before she could answer, he suggested a possible partnership between T-Mist and Walgreens, with Walgreens serving as a contract pharmacy provider. He reminded her that Walgreens was in the retail pharmacy business and had been in business for over 100 years, growing in size to over 6000 stores. Dispensing pharmaceuticals was their business and they were very good at it. He explained that Walgreens had partnered with another health care provider in Connecticut to the benefit of both the health care provider and Walgreens.

After returning from the conference, Montanaro shared her conversation with the Walgreens executive with Bourassa and Balasco. Both suggested she get more information. She then contacted Ken Anderson who put her in touch with the Walgreens central offices. Walgreens explained that they wanted to take over the dispensing of formulary prescribed by T-Mist physicians, through their network of retail pharmacies. They would charge patients the same price that T-Mist was charging. Additionally, they would provide an expanded set of medications that 
were not available through the in-house pharmacy or through the remote dispensing sites. These medications would be provided at $340 \mathrm{~B}$ prices. This would relieve T-Mist from redirecting funds from medical and social service programs in 2007 to support the projected $\$ 250,000$ operating deficit of the pharmacy. The Walgreens proposal would also free up space at both the Woonsocket treatment facility and the remote locations.

As Montanaro discussed the Walgreens proposal with her staff, Sam Limiadi pointed out that although Walgreens had twenty retail locations in Rhode Island, there were no pharmacies located near their south county health center. He wondered where the patients that were treated at this facility would get their medications.

While trying to decide what the most prudent course of action would be, Linda Reilly, Vice President of Development called her. "Maria, I understand you are about to make a commitment to Walgreens to take over operations of our pharmacy." Montanaro quickly stopped Linda from continuing. She was more than a little upset that news about the discussions with Walgreens had leaked out. "Linda, I do not know what you have heard, but I have not yet made any decision as to what will be the future of the pharmacy. We have a number of options we are considering."

Linda continued, "I'm glad to hear that. I would like to point out that if one of your options is to look to an outside organization for assistance, considering a partnership with Walgreens may jeopardize the relationship we have spent years building with CVS. They have provided over $\$ 100,000$ of support in terms of funding, products, and services in just the last year alone. This coming year we had intentions of asking them to double that amount. If they hear that we are considering a partnership with Walgreens, which happens to be their major competitor, I expect they will reassess their relationship with us."

"Linda, thank you for the information. The relationship you have been able to develop over the years with CVS is important to T-Mist and we do not want to jeopardize it", responded Montanaro. She immediately placed calls to Bourassa, Balasco, and Limiadi and shared with them Reilly's concerns. She knew only too well that T-Mist depended on the goodwill and philanthropy of area for-profit organizations. After much effort, they had been able to cultivate a relationship with CVS, and were able to solicit donations of both services and products. They expected that this philanthropy would increase in the future. Limiadi suggested that they should contact officials at CVS and explain what T-Mist's goals were and provide CVS with an opportunity to "react" to a potential partnership with Walgreens. The other key managers agreed that CVS should be contacted.

Montanaro informed Linda of her decision to contact CVS. She also indicated that if CVS were willing to discuss a similar type of arrangement, she and her senior staff would delay making any decision concerning the pharmacy. She was sympathetic with her VP's desire to maintain the relationship with CVS, realizing she had also committed much time and effort to developing the relationship with the retail pharmacy giant.

The next day, Montanaro placed a call to Chris Bodine, President of CVS and explained T-Mist's desire to explore privatizing their pharmacy operations. She also informed him that T-Mist was involved in negotiations with another pharmacy chain (which she did not identify) to take over the operations of the pharmacy. She asked Bodine if CVS would have an interest in discussing this type of arrangement. Bodine indicated that CVS would be interested and that they were actively seeking relationships of this type. He explained that T-Mist, being in the back yard of CVS corporate headquarters, would be an attractive potential partner and could provide CVS with experience in an area they had targeted for expansion. He emphasized that CVS could offer T-Mist patients the most expansive network of pharmacies in the state, in addition to having just developed an advanced information system to manage $340 \mathrm{~B}$ pricing.

CVS Caremark was the nation's largest retail pharmacy chain, with approximately 6,200 stores across 38 states. Within the state of Rhode Island, CVS had nearly 50 retail pharmacies, with 5 located in South County. CVS generated over $68 \%$ of it's approximately $\$ 37$ billion net revenue from the pharmacy business, and in 2006 filled more than one of every seven retail prescriptions in the United States. Their "ExtraCare Program" had over 50 million cardholders, making it the largest retail loyalty program in the country. Over the past two years, CVS had completed the integration of over 1,200 Eckerd and 700 Sav-on and Osco drugstores as part of an aggressive national growth program. 
Time was running out. The Board meeting was approaching and she had not yet decided which option was best to deal with the pharmacy problems. As the CEO of Thundermist Health Center, the recommendation to the Board was her responsibility; however the advice of her key executives was critical to her decision. Montanaro asked Bourassa, Limiadi, Reilly, and Balasco to meet her in her office that afternoon. Decisions had to be made.

\section{EPILOGUE}

On June 25, 2007, Thundermist announced that it had turned over its in-house pharmacy program to CVS Caremark Corporation. According to Montanaro, the reason behind this move was to eliminate the in-house pharmacy's growing deficit and still provide pharmaceuticals at low prices to patients.

The relationship they had negotiated required CVS to take over retail operations of the in-house pharmacy in the Woonsocket center and to provide pharmaceuticals to patients at the remote sites using retail pharmacies located close to T-Mist's South County and West Warwick facilities. The relationship with the northwest center was not included in the agreement as CVS was unable to provide convenient access to pharmaceuticals through a local retail store. CVS agreed to provide the 100 formularies that were contained in the remote dispensing devices at the same prices that Thundermist had been charging. Montanaro felt that CVS would also be able to provide a larger variety of products and services to their patients than their own in-house pharmacy and remote dispensing devices were able to provide, and at reduced prices.

\section{AUTHOR INFORMATION}

Charles J. Quigley Jr. is a Professor of Marketing at Bryant University. His research interests include strategic issues of service marketing, business-to-business marketing and profit/nonprofit marketing. Dr. Quigley has published previous research in a number of journals including the Journal of Marketing Theory and Practice, Journal of Marketing Management, Journal of Marketing for Higher Education, Journal of Services Marketing, among others.

Frank G. Bingham, Jr., is a Professor of Marketing at Bryant University. Dr. Bingham's research interests include business-to-business marketing, profit/non-profit marketing, services marketing, and the marketing of higher education. He has published in the Journal of Marketing Theory and Practice, Journal of Marketing for Higher Education, Journal of Services Marketing, among others. He is also the author of several textbooks on business-tobusiness marketing.

\section{REFERENCES}

1. Centers for Medicare and Medicaid. Available at www.cms.hhs.gov. Accessed in August 2006.

2. $\quad$ CVS Corporation Web Site, http://www.cvs.com/corpInfo/index.html, Accessed December 2007.

3. Kaiser Family Foundation and the Health Research and Educational Trust, www.nchc.org/facts/cost.shtml).

4. National Center for Health Statistics. Health, Unites States, 2005. Washington DC: U.S. Government Printing Office: 360.

5. Robinson, David F., Grant T. Savage, and Kim Sydow Campbell. Organizational Learning, Diffusion of Innovation, and International Collaboration in Telemedicine. Health Care Management Review.2003; 28(1):68-78.

6. Thundermist Health Center Comprehensive Pharmacy Network, Needs Assessment, Woonsocket RI, Thundermist Health Center; 2005.

7. Thundermist Health Center Internal Documents, Woonsocket RI, Thundermist Health Center; 2005.

8. U.S. Census Bureau News. Income Climbs, Poverty Stabilizes, Uninsured Rate Increases. Available at http://www.census.gov/Press-Release/www/releases/archives/income-wealth/. Accessed August 2006.

9. U.S. Census Bureau. Historic Income Tables - Households 1975-2004. Washington DC: U.S. Government Printing Office; 2004.

10. U.S. Census Bureau. Income, Poverty, and Health Insurance Coverage in the United States: 2003. Washington DC: U.S. Government Printing Office; 2004. 